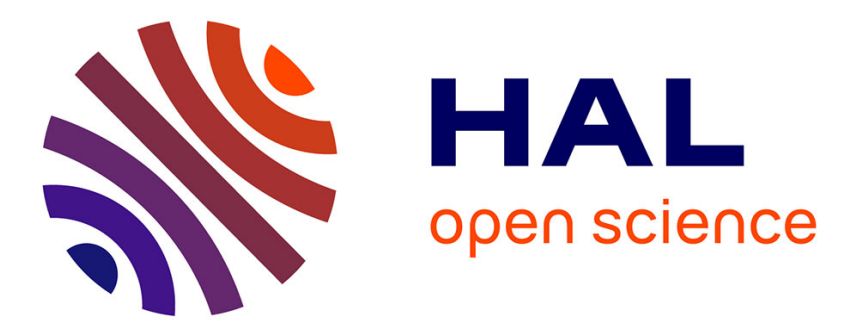

\title{
Hydrolysis and fermentation steps of a pretreated sawmill mixed feedstock for bioethanol production in a wood biorefinery
}

Maarouf Abdou-Alio, O Tugui, L Rusu, Agnès Pons, Christophe Vial

\section{- To cite this version:}

Maarouf Abdou-Alio, O Tugui, L Rusu, Agnès Pons, Christophe Vial. Hydrolysis and fermentation steps of a pretreated sawmill mixed feedstock for bioethanol production in a wood biorefinery. Bioresource Technology, 2020, 310, pp.123412. 10.1016/j.biortech.2020.123412 . hal-03086115

\author{
HAL Id: hal-03086115 \\ https://hal.uca.fr/hal-03086115
}

Submitted on 22 Dec 2020

HAL is a multi-disciplinary open access archive for the deposit and dissemination of scientific research documents, whether they are published or not. The documents may come from teaching and research institutions in France or abroad, or from public or private research centers.
L'archive ouverte pluridisciplinaire HAL, est destinée au dépôt et à la diffusion de documents scientifiques de niveau recherche, publiés ou non, émanant des établissements d'enseignement et de recherche français ou étrangers, des laboratoires publics ou privés.

\section{(c)(1)}

Distributed under a Creative Commons Attribution| 4.0 International License 
1 Hydrolysis and fermentation steps of a pretreated sawmill mixed feedstock for bioethanol production in a wood biorefinery

3

4 Maarouf ABDOU ALIO ${ }^{1, *}$, Oana-Cristina TUGUI ${ }^{2}$, Lacramioara RUSU ${ }^{2}$, Agnès PONS ${ }^{1}$,

5 Christophe VIAL ${ }^{1}$

6 ' ${ }^{1}$ Université Clermont Auvergne, CNRS, Sigma Clermont, Institut Pascal, F-63000, Clermont7 Ferrand, France.

${ }^{2}$ University "Vasile Alecsandri" of Bacău, Faculty of Engineering, Chemical and Food

9 Engineering Department, Bacău, Romania.

\section{Abstract}

The aim was to demonstrate the feasibility of second-generation bioethanol production using for the very first time a sawmill mixed feedstock comprising four softwood species, representative of biomass resource in Auvergne-Rhône-Alpes region (France). The feedstock was subjected to a microwave-assisted water/ethanol Organosolv pretreatment. The investigation focused on the enzymatic hydrolysis of this pretreated sawmill feedstock (PSF) using Cellic ${ }^{\circledR}$ Ctec2 as the enzyme, followed by fermentation of the resulting sugar solution using Saccharomyces cerevisiae strain. The cellulose-rich PSF with 71\% w/w cellulose content presented a high saccharification yield (up to 80\%), which made it perfect for subsequent fermentation; this yield was predicted vs. time up to $5.2 \% \mathrm{w} / \mathrm{v}$ PSF loading using a mathematical model fitted only on data at $1.5 \%$. Finally, high PSF loading (7.5\%) and scaleup were shown to impair the saccharification yield, but alcoholic fermentation could still be carried out up to $80 \%$ of the theoretical glucose-to-ethanol conversion yield.

"Corresponding author.

Email address: maarouf.abdou_alio@uca.fr (Maarouf ABDOU ALIO) 
1 Keywords: Organosolv pretreatment, mixed sawdust, cellulose hydrolysis, fermentation,

2 lignocellulosic bioethanol

\section{1. Introduction}

4 Biofuels, in particular second-generation biofuels, have gained interest from academic research, government, and large companies nowadays. Lignocellulosic biofuel production is indeed widely accepted in the society as it is perceived as non-competitive with agri-food (Bryngemark, 2019). Also, these biofuels represent a renewable option to replace the depleting oil supply and can help mitigate the climate change impacts resulting from fossil fuels. For low-cost biofuel production, lignocellulosic biomass is a potential candidate feedstock because its price is estimated as being the lowest compared to starch which is presently used to produce bioethanol (Chovau et al., 2013). Auvergne Rhône-Alpes is one of the largest forest regions in France with a forest density estimated at $43910^{6} \mathrm{~m}^{3}$. As a consequence, the local wood processing industries generate a significant amount of sawdust or other wastes that are not valorized otherwise than being burnt for heat in this region. An alternative way of valorization of this waste is the production of second-generation bioethanol in order to develop a reliable and sustainable regional energy model that fits well with the energy transition policy and the fight against climate change. This could have the advantage of promoting the valorization of local wood waste with a view to setting up a forest biorefinery. Beyond the regional impact, large-scale second-generation biofuel facilities could also contribute to enhance the security of energy supply and, more generally, to strengthen the world economy (Sarks et al., 2014).

To increase lignocellulose digestibility, numerous lignocellulose pretreatment methods have been matured. Among all the thermomechanical and chemical processes, Organosolv pretreatment can be considered to be an eco-friendly and attractive method to remove lignin 
1 from lignocellulose materials using pure or diluted organic solvents in order to purify

2 cellulose (Akgul and Kirci, 2009; Zhao et al., 2009). Thus, Organosolv pretreatments are very

3 efficient techniques for the production of second-generation bioethanol because they can

4 provide both cellulose and lignin with high purity, and minimize at the same time the

5 production of fermentation inhibitors (Mupondwa et al., 2017).

6 As a subsequent step to pretreatment, hydrolysis transforms the cellulose and the remaining hemicelluloses into fermentable sugars. The enzymatic hydrolysis step has been recognized as a major techno-economic bottleneck in the whole wood-to-ethanol bioconversion process. For example, the enzymatic hydrolysis and fermentation of starch-based substrates (e.g. corn) are generally performed at a substrate loading greater than $20 \%$ solids, leading to a final ethanol content of the order of $10 \%$ (w/v) (Zhang et al., 2009). Conversely, the standard enzymatic hydrolysis of lignocellulosic biomass is generally carried out at a substrate proportion of less than $5 \%$ solids content. This results in a concentration of sugar lower than $4 \%(\mathrm{w} / \mathrm{v})$ in the hydrolysate and, subsequently, an ethanol concentration less than $2 \%(\mathrm{w} / \mathrm{v})$.

Elevating the substrate loading during the enzymatic hydrolysis should result in an increase in the concentration of sugar and a higher final ethanol concentration after fermentation. This strategy will allow cutting the costs of the bioconversion process, e.g. by reducing the operational and capital expenditures of hydrolysis and fermentation, and by saving energy in the distillation/evaporation and other downstream processes. When proceeding to a technoeconomic assessment on enzymatic hydrolysis, Stenberg et al. (2000) and Wingren et al. could diminish the total production cost by almost $20 \%$. A further increase in the substrate proportion could then result in even greater savings. Nevertheless, their investigation conducted at that time failed to achieve effective hydrolysis at a substrate proportion greater than $10 \%$ using simultaneous saccharification and fermentation approaches (SSF), or separate 
1 hydrolysis and fermentation (SHF). The authors had thus identified several impediments to

2 high substrate hydrolysis, among which the cases were: $(i)$ a high concentration of fibrous materials reduces the mass transfer rate; (ii) a high level of inhibiting substances is produced; (iii) a high sugar concentration leads to severe inhibition effects of the finished products. Similarly, Qiu et al. (2017) concluded that increasing initial solid concentrations above $2 \%$ w/w reduced significantly the conversion rate.

To circumvent these issues, process optimization though mathematical modeling is the key. Thus, various models have been proposed to describe enzymatic hydrolysis. The simplest approach considers conventional or modified Michaelian kinetics with competitive, noncompetitive or uncompetitive inhibition, whereas the most complex modeling strategy may take cellulose polymerization degree or particle size and morphology through a population balance into account (Zhang et al., 2014; Lebaz et al., 2015). Alternative mechanistic models sometimes account for chemical or physical phenomena which may affect the kinetics of enzymatic hydrolysis of cellulose, such as concurrent reactions (Tsai et al., 2014), adsorption equilibria without or with inactivation of adsorbed cellulase (Kadam et al., 2004; Wang and Feng, 2010; Tervasmäki et al., 2017), fractal kinetics for heterogeneous reactions (Ye and Berson, 2011), or mixing conditions through mass transfer rate (Kinnarinen et al., 2012; Wojtusik et al., 2016). It must be pointed out that the complete mechanism of enzymatic hydrolysis is still unknown, and could also depend on the type and purity of the substrate and of the enzymes.

In this work, the goal was, therefore, to hydrolyse and ferment an industrial and readily available sawmill feedstock previously pretreated through an "Organosolv pretreatment" based on an original microwave heating (Alio et al., 2019). This process presents the simultaneous advantage to produce high quality lignin that can be used in the closed-loop biorefinery concept with potentially high added-value coproducts. So, this study focussed first 
1 on glucose concentration and cellulose-to-glucose conversion yield as a function of the

2 operating parameters in a batch enzymatic hydrolysis process; from these data, a model aimed to predict the glucose concentration, and the cellulose-to-glucose conversion yield could be developed. Then, the feasibility of bioethanol production by fermentation using the obtained enzymatic hydrolysate was studied using the yeast Saccharomyces cerevisiae. Finally, the scale-up from flasks to batch bioreactors of the hydrolysis and fermentation steps for the production of second-generation bioethanol was investigated.

\section{Materials and methods}

\subsection{Feedstocks and reagents}

Organosolv pretreated samples of mixed sawdust from four softwood species were used: fir, spruce (Picea abies), Scots pine (Pinus sylvestris), and Douglas fir, respectively. The sawdust mixture was provided by a local sawmill company (Les Scieries du Centre Marcel Esbelin et Cie), located in Cournon d'Auvergne (France), and was extracted from a monthly feedstock. The initial composition of the sawdust mixture was determined to be $44.3 \% \pm 0.5 \%$ glucan (dry wt.), $25.6 \% \pm 0.2 \%$ hemicellulose (dry wt.), $26 \% \pm 3 \%$ Klason lignin (dry wt.), ash content $0.3 \% \pm 0.2 \%$ (dry wt.), and 3.2\% $\pm 0.2 \%$ extractives (dry wt.) (Alio et al., 2019).

The pretreated mixed sawdust was subjected to a microwave-assisted Organosolv pretreatment in which four parameters were studied to optimize the fractionation of the wood, including cellulose recovery yield and cellulose purity, lignin recovery yield, and the absence of formation of inhibitors; these parameters were, namely: (i) the concentration of sulfuric acid $\left(\mathrm{H}_{2} \mathrm{SO}_{4}\right)$ as a catalyst; (ii) the ethanol/water ratio in the extraction solvent; (iii) the treatment temperature; (iv) the process time. The optimal conditions determined experimentally on sawdust could be summarized as follows: an ethanol/water ratio of 60:40 with $0.25 \% \mathrm{H}_{2} \mathrm{SO}_{4}$ for one-hour extraction at $175^{\circ} \mathrm{C}$. These conditions made it possible to 
1 remove $50 \%$ of the lignin while preserving $82 \% \pm 3 \%$ of the initial cellulose with a purity of

$271 \% \pm 3 \% \mathrm{w} / \mathrm{w}$. The composition of the pretreated sawdust mixture was then: $70.6 \% \mathrm{w} / \mathrm{w}$

3 cellulose, $9.8 \% \mathrm{w} / \mathrm{w}$ hemicellulose, and $19.6 \% \mathrm{w} / \mathrm{w}$ lignin, as determined by strong acid

4 hydrolysis (Alio et al., 2019).

\subsection{Enzymes and other chemicals}

The enzymatic hydrolysis was carried out using an enzyme preparation: Cellic ${ }^{\circledR} \mathrm{Ctec} 2$ (Novozymes, Denmark). The activity on filter paper fibers (FPU) was determined as described by Ghose (1987), and the protein content as described by Bradford (1976). Thus, the obtained activity was found to be $189 \mathrm{FPU} / \mathrm{mL}$ and the protein content as $77.0 \pm 0.3$ $\mathrm{mg} / \mathrm{mL}$. The chemicals, such as acetate buffer solution ( $\mathrm{pH} 4.8)$, streptomycin antibiotics and other chemicals (reagent grade) were purchased from Sigma-Aldrich (France).

\subsection{Enzymatic hydrolysis}

All enzymatic hydrolysis runs were performed according to the NREL standard procedure (Selig, 2008). All experiments were carried out using the pretreated sawdust mixture obtained through the best pretreatment previously described. Depending on the assays, pretreated sawdust mixture solids could be oven-dried $\left(110^{\circ} \mathrm{C}\right.$ for $\left.24 \mathrm{~h}\right)$ or not. Enzymatic hydrolysis of pretreated mixture was performed in $150 \mathrm{~mL}$ Erlenmeyer flasks under batch conditions at $50^{\circ} \mathrm{C}$ in a shaker water bath (Julabo SW22, France) with a mixing speed of $180 \mathrm{rpm}$ according to Mukasekuru et al. (2018). Hydrolysis was carried out in a $50 \mathrm{mM}$ acetate buffer solution at $\mathrm{pH} 4.8$ using the cocktail of enzyme mentioned above and streptomycin antibiotics were added to prevent contamination. Different biomass loading concentrations were tested: $1.5 \%$, $3.75 \%, 4.5 \%$, and $5.2 \%$ w/v. These were selected because the homogeneity of the liquidsolid dispersion could be maintained, despite the increase in viscosity of this dispersion in this range, which was not the case at higher solid substrate loadings. The carbohydrate profile in 
1 the hydrolysate was determined using HPLC, as described below in section 2.6. The

2 enzymatic hydrolysis yield was calculated using the following equation:

3 Cellulose - to - glucose conversion yield $(\%)=100 \times \frac{C_{\text {glucose }}\left(\frac{g}{L}\right) \times V_{\text {liquid }}(L) \times 0.90}{m_{\text {solids }}(g) \times x_{\text {cellulose }}}$

4 where $C_{\text {glucose }}$ is the concentration of glucose determined by HPLC (g/L), $V_{\text {liquid }}$ represents 5 the volume of the liquid (L), 0.90 is the correction factor for the conversion of cellulose-to-

6 glucose, $x_{\text {cellulose }}$ is the mass fraction of cellulose (g cellulose/g solid) and $m_{\text {solids }}$ is the mass 7 of dry solids (g).

\subsection{Fermentation}

For the fermentation step, the yeast Saccharomyces cerevisiae ATCC 7754 was used. The strain was supplied as a lyophilizate, taken in a sterile water and spread onto YM agar-agar (Yeast Medium, Difco 0712-01-8), before incubated 24 hours at $28{ }^{\circ} \mathrm{C}$. The strain was then stored at $4^{\circ} \mathrm{C}$ and subcultured on a Petri dish 24 hours, before being used in the culture vessels (Bahry et al., 2017). Then, the fermentation itself was carried out in $125 \mathrm{~mL}$ Erlenmeyer flasks and the hydrolysate obtained after the enzymatic step was used as a culture medium. First, the culture medium (denoted as "unenriched hydrolysate" or UE.H) was considered as the control assay in order to assess the intrinsic potential of the hydrolysate to undergo growth and fermentation. The second culture medium (denoted as "enriched hydrolysate" or E.H) was supplemented with additional elements defined by Kristiansen (1994). The biomass growth was followed by spectrophotometry at $550 \mathrm{~nm}$ (Biomate $3 \mathrm{~S}, \mathrm{UV} / \mathrm{vis}$ spectrophotometer, Thermo Scientific, France), and the dry matter was determined by gravimetry. 


\subsection{Enzymatic hydrolysis and fermentation scale-up}

For the scale-up experiments, enzymatic hydrolysis was conducted as described in section $\mathbf{2 . 3}$ using a biomass concentration of $7.5 \% \mathrm{w} / \mathrm{v}$ in a $1000 \mathrm{~mL}$ glass bottle with a working volume of $800 \mathrm{~mL}$; this higher substrate loading was allowed by the improved mixing conditions, so as to maintain spatially homogenous reaction rate and concentrations for sampling purpose. Then, the fermentation step was carried out in a $500 \mathrm{~mL}$ bioreactor (Infors HT, Multitron 2) with a working volume of $400 \mathrm{~mL}$. The hydrolysate obtained after the enzymatic hydrolysis was completed as described in section 2.4. Only (E.H) was used as the culture medium.

\subsection{Sugar, ethanol and inhibitors quantification}

In order to monitor the evolution of the carbohydrate concentrations during the enzymatic hydrolysis and during fermentation, samples of $1 \mathrm{~mL}$ were taken at specific time intervals. In the case of enzymatic hydrolysis, enzymes were first deactivated in all samples at $100{ }^{\circ} \mathrm{C}$ for $10 \mathrm{~min}$. Prior to analysis, each sample was deproteinized to prevent clogging of chromatography column. For this purpose, $125 \mu \mathrm{L}$ of barium hydroxide solution $\left(\mathrm{Ba}(\mathrm{OH})_{2}\right.$; $0.3 \mathrm{M})$ and $125 \mu \mathrm{L}$ of zinc sulfate solution $\left(\mathrm{ZnSO}_{4}, 7 \mathrm{H}_{2} \mathrm{O} ; 5 \% \mathrm{w} / \mathrm{v}\right)$ were added to the samples. After centrifugation (Thermo scientific, France) for 5 minutes at 10,000 $g$, the supernatant was filtered using a $0.2 \mu \mathrm{m}$ cellulose acetate filter (Chromafil, Germany). The concentrations of glucose, cellobiose, xylose, ethanol, and by-products (formic acid, levulenic acid, and acetic acid) were measured using a high-performance liquid chromatography (HPLC) device (1260 Infinity Quaternary LC system, Agilent Technology, USA). This was equipped with two ionic exclusion columns in series (Rezex ROA 300×7.8 mm, Phenomenex, USA). The mobile phase was a solution of $5 \mathrm{mM}$ sulfuric acid at $0.7 \mathrm{~mL} / \mathrm{min}$ flowrate.

Products detection was done using a refractometer (HP 1100 series, Agilent Technologies, USA). 


\subsection{Data analysis and number of samples replicate}

All the results reported for batch hydrolysis and fermentation are the mean values of at least two replicates based on two batches of repeated experiments under the same conditions. Three samples were taken for each time point. The mean and standard deviation were calculated by

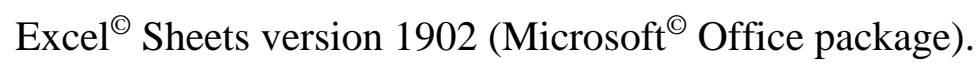

\subsection{Enzymatic hydrolysis kinetic modeling}

As described in section 1, various models had been proposed in the literature to describe this process. A rapid analysis of preliminary data had shown that the rate of glucose production could not be fitted by a Lineweaver-Burk plot, which suggested a more complex mechanism than classical or modified Michaelian kinetics as a function of substrate content. Similarly, glucose production rate increased with substrate loading, so that the effect of enzyme mass transfer resistance never seemed to become predominant, despite the increase in dispersion viscosity. Actually, the initial reaction rate appeared to be nearly proportional to the initial substrate loading, while reaction rate decreased over time when substrate consumption proceeded, indicating a limitation by enzyme availability. Among the possible mechanistic models able to simulate the enzymatic hydrolysis of the pretreated sawdust mixture with the enzymatic cocktail, an approach similar to that proposed by Kadam et al. (2004), considering enzyme adsorption, was adopted. Enzymatic hydrolysis of lignocellulosic materials is a heterogeneous reaction where the adsorption of enzymes is one of the key steps in the overall reaction mechanism. Thus, hydrolysis can be seen as a succession of two rate-limited reaction steps schematized in the following equation: a heterogeneous reaction involving endoglucanases $(\mathrm{EG})$ and cellobiohydrolases $(\mathrm{CBH})$ to produce cellobiose, and then a homogeneous reaction where cellobiose is transformed into glucose by $\beta$-glucosidases (BGL), as follows: 
2 The transformation rate of the cellulose $r_{1}$ by the pair EG/CBH considering the (competitive)

3 inhibition effect by the products (cellobiose and glucose) is given by:

4

\section{Cellulose $(\mathrm{EG} / \mathrm{CBH})$--- $r_{1^{---}}>$Cellobiose $(\mathrm{BGL})$--- $r_{2}--->$ Glucose}

$$
r_{1}=\frac{k_{1 r} \times E_{1 b} \times R_{S} \times S}{1+\frac{C_{C}}{K_{1 I C}}+\frac{C_{G}}{K_{1 I G}}}
$$

Then, the rate of transformation of cellobiose into glucose $r_{2}$ by BGL is described by a Michaelian kinetics:

$$
r_{2}=\frac{k_{2 r} \times E_{2} \times C_{c}}{K_{2 M}\left(1+\frac{C_{G}}{K_{2 I G}}\right)+C_{c}}
$$

where $S, C_{c}, C_{G}, E_{1 b}$ and $E_{2}$ represent the respective concentrations of substrate, cellobiose and glucose and of the EG/BGL and BGL enzyme species $\left(\mathrm{g} \cdot \mathrm{kg}^{-1}\right)$, the subscript $b$ corresponding to bound enzymes. In these equations, $K_{i I G}, K_{1 I C}$ represent the inhibition constants of glucose in reaction $i$ and of cellobiose $\left(\mathrm{g} \cdot \mathrm{kg}^{-1}\right)$, respectively; $K_{2 M}$ designates the enzyme Michaelis

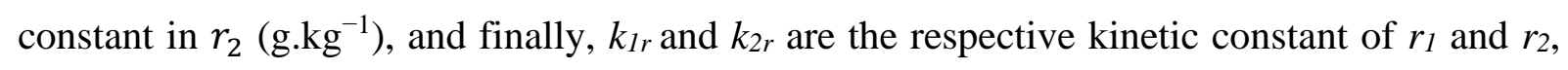
and $R_{S}$ the substrate reactivity. Adsorption was modelled using a Langmuir isotherm, which assumes that equilibrium is rapidly reached and can be described by

$$
E_{1 b}=\frac{E_{1 \max } \times K_{1 a d} \times E_{1} \times S}{1+K_{1 a d} \times E_{1}}
$$

where the amount of free enzyme $E_{l}$ is related to the amount of bound enzyme $E_{l b}$ by the enzyme conservation law and two additional parameters: $K_{\text {lad }}$ the dissociation constant for the enzyme/substrate complex, and $E_{1 \max }$ the maximum mass of enzyme that can adsorb onto cellulose, both expressed in g enzyme/g cellulose. Equation (4) also expresses the relationship between $E_{1 b}$ and substrate concentration $S$.

From this model, a set of differential equations vs. time was derived, which was solved using a first-order Euler forward algorithm. The equations were finally coded and solved using the MATLAB programming environment. Langmuir adsorption parameters were derived from 
1 Kadam et al. (2004), while the kinetic parameters were deduced by fitting the model with 2 experimental data.

\section{3. Results and discussion}

\subsection{Enzymatic hydrolysis}

5

\subsubsection{Effect of size reduction on the dried substrate}

Prior to the preliminary assays of enzymatic hydrolysis, pretreated sawdust mixture was ovendried $\left(110^{\circ} \mathrm{C}\right.$ for $\left.24 \mathrm{~h}\right)$ for dosage purpose (Alio et al., 2019). Then, this was subjected to enzymatic hydrolysis, conducted at $1.5 \%(\mathrm{w} / \mathrm{v})$ substrate loading, with an enzyme content of $50 \mathrm{FPU} / \mathrm{g}$ of dry pretreated sawdust mixture for two different particle sizes. A first fraction of the solids was crushed using a domestic blender to reach an average particles size passing through $0.5 \mathrm{~mm}$ sieve (IG), while the other one was kept intact with an average size larger than $0.5 \mathrm{~mm}$ (SG). Thus, the hydrolysis of SG resulted in a glucose concentration about $1.6 \pm$ $0.3 \mathrm{~g} / \mathrm{L}$, while the hydrolysis of IG produced approximately $3.1 \pm 0.1 \mathrm{~g} / \mathrm{L}$ glucose in the final hydrolysate. When the cellulose-to-glucose conversion yield was calculated (Fig. 1Erreur ! Source du renvoi introuvable.), it was found that only $12.4 \% \pm 0.7 \%$ of the cellulose present in the SG pretreated sawdust mixture was converted to glucose within 8 days of incubation. Reducing the substrate particle size to a smaller granulometry (IG) doubled cellulose-toglucose conversion yield, which reached approximately $24 \% \pm 1 \%$. Other studies had already investigated the effect of particle size on the rate of enzymatic hydrolysis of cellulose (Dasari and Berson, 2007; Fu et al., 2018; Sangseethong et al., 1998; Yeh et al., 2010). According to Sangseethong et al. (1998), reducing particle size from 0.10 to $0.02 \mathrm{~mm}$ at $0.1 \%(\mathrm{w} / \mathrm{v})$ substrate proportion almost doubled the saccharification rate of cellulose (Avicel).

Nevertheless, with the same size reduction, only $50 \%$ increase in the saccharification rate was observed at $2 \%(\mathrm{w} / \mathrm{v})$ substrate concentration according to Yeh et al. (2010). Finally, Zeng et 
1 al. (2007) also reported that reduction of size from 425-710 to 53-75 $\mu \mathrm{m}$ raised glucose

2 production rate from 0.1 to $0.18 \mathrm{~g} / \mathrm{L} / \mathrm{h}$. In agreement with the literature, experimental results

3 obtained in this study highlight that a reduction in particle size significantly enhanced the

4 hydrolysis rate of cellulose. However, the grinding process may be costly because of its

5 important power requirements that counterbalance its beneficial effects on cellulose-to-

6 glucose conversion yield (Fu et al., 2018; Shastri et al., 2014). Shastri et al. (2014) determined

7 the evolution of the cost of Miscanthus and switchgrass size reduction as a function of output

8 particle size using a hammer mill for the following particle sizes: $1,2,4,6,8,12.7,16,25.4$

$9 \mathrm{~mm}$. According to this study (Table 1), the costs were dramatically increased when particle

10 size was reduced below $2 \mathrm{~mm}$. However, for both the Miscanthus and the switchgrass, the

11 optimal particle size ranged between 4 and $6 \mathrm{~mm}$, and the corresponding total cost (grinding, storage and transportation) were about \$55 and \$61 per ton for Miscanthus and switchgrass, respectively.

\subsubsection{Effect of substrate humidity}

Fig. 1 also displays the evolution of the cellulose-to-glucose conversion yield as a function of time for two different substrate humidity values: oven-dried pretreated substrate, and wet pretreated substrate. Both runs were performed on $0.5-1 \mathrm{~mm}$ pretreated substrate particule size to cut the cost of the grinding process, at $1.5 \%(\mathrm{w} / \mathrm{v})$ substrate concentration and an enzyme loading of $50 \mathrm{FPU} / \mathrm{g}$ of pretreated substrate. Regarding these results for both cases, it can be noticed that the enzymatic hydrolysis was strongly affected by the humidity level. So, a low conversion rate was observed with the dried pretreated substrate with a maximum conversion yield reached after 8 days of $12.4 \pm 0.5 \%$, while a value of $56 \% \pm 2 \%$ was reached for the wet pretreated substrate in the same period. There is no doubt that this difference was due to the low digestibility of the dried substrate, linked itself to a structure modification of 
1 the substrate as a direct impact of the drying process. According to Kang et al. (2018), the

2 drying step of $\mathrm{NaOH}$ pretreated Eucalyptus samples caused a decrease in the volume and the surface area of the porosity of wood of about $45 \%$ of the initial value. So, the pore volume and surface area of dried biomass substrates should not provide sufficient access to the

enzymes for adsorption onto the cell surfaces, thus significantly slowing down the enzymatic hydrolysis of the cellulose. Moreover, these authors also explained the structure modification as a result of a significant pore collapse in the cellulose fibers during the oven-drying procedure, based on the low adsorption capacity of dried pretreated Eucalyptus samples.

Bhagia et al. (2018) also reported that drying possibly caused pore collapse and thereby impaired cellulose accessibility. In their investigations, Huang et al. (2010) advocated, however, that the changes in the chemical composition might also bean alternative reason, as the removal of lignin and hemicellulose had also a significant effect on the surface area and the pore size distribution. Another possible reason in the present study could be linked to the Organosolv pretreatment that did not significantly delignify the raw sawdust material, as a significant fraction of the lignin remained in the resulting pretreated substrate $(39 \% \pm 1 \%$ w/w of the raw feedstocks lignin content, which represents $20 \% \pm 2 \% \mathrm{w} / \mathrm{w}$ of the pretreated substrate). High lignin content is, indeed, known to hinder enzymatic hydrolysis through the nonproductive binding of cellulase enzymes. Likewise, as a non-cellulose component, hemicellulose is generally considered as a physical hindrance in enzymatic hydrolysis of cellulose, and prevents the access of cellulase from cellulose surface (Qiu et al., 2017).

Finally, it emerges from experimental data that there is no need to dry the pretreated substrate, which saves energy and enhances hydrolysis rate at the same time, and that hydrolysis must be carried out rapidly after pretreatment to prevent natural drying. 


\subsubsection{Effect of enzyme loading on the wet substrate}

The wet pretreated sawdust mixture was hydrolyzed at both 50 and 70 FPU/mL enzyme content under the same conditions as applied before, i.e. $1.5 \%$ substrate loading and particle size between $0.5-1 \mathrm{~mm}$. As shown in Fig.1Erreur ! Source du renvoi introuvable., it is apparent that increasing enzyme loading leads to an increase in sugar concentration and cellulose-to-glucose conversion rate. Thus, the pretreated sawdust with the higher enzyme loading demonstrated a higher hydrolysability which reached nearly $68 \%$ of the available cellulose. Hydrolysis using 70 FPU/g enzyme loading also yielded a greater glucose concentration that reached $7.8 \pm 0.2 \mathrm{~g} / \mathrm{L}$ in the hydrolysate after 10 days, while $5.7 \pm 0.5 \mathrm{~g} / \mathrm{L}$ and only about $50 \%$ conversion yield were obtained at $50 \mathrm{FPU} / \mathrm{g}$. Thus, $50 \mathrm{FPU} / \mathrm{g}$ substrate induced a $28 \%$ reduction in enzyme loading in comparison to the maximum value, which reduced the final glucose amount by about $27 \%$ (from 8 to $6 \mathrm{~g} / \mathrm{L}$ ), i.e. approximately the same value. The same conclusions were reported by Zhang et al. (2009) when conducting an enzymatic hydrolysis on pretreated hardwood substrates with three different enzyme charges (3, 10 and 20 FPU/g). Moreover, in another study by Bhagia et al. (2018), 1\% glucan loading (Avicel, 97\% cellulose and 3\% xylan) was enzymatically hydrolyzed using Accelerase ${ }^{\circledR} 1500$ at two different enzymes loadings, 5 and $30 \mathrm{mg}$ of enzyme/100 $\mathrm{ml}$ of solvent, designated as low and high cellulase loadings, respectively; as a result, these authors observed that the kinetic curves displayed a cellulose conversion yield of $60 \%$ for up to 17 days of enzymatic hydrolysis at low enzyme loading, while the conversion yield reached $97 \%$ for up to 9 days at high enzyme loading. Similar results were also reported in other studies conducted in quite identical experimental conditions of the present work (Stenberg et al., 2000; Zhang et al., 2009). As a conclusion, enzymatic hydrolysis remains strongly dependent on enzyme content, even though $1.5 \%(\mathrm{w} / \mathrm{v})$ substrate loading used is the lowest value used in this work. 


\subsubsection{Effect of wet substrate loading}

Erreur! Source du renvoi introuvable. depicts the evolutions of glucose concentration and hydrolysis yield as a function of time for four different wet pretreated substrate loadings (1.5\%, $3.75 \%, 4.5 \%$, and $5.2 \% \mathrm{w} / \mathrm{v}$ ) with a particle size between 0.5 and $1 \mathrm{~mm}$, at $50 \mathrm{FPU} / \mathrm{g}$ to. Basically, it can be noted that, in general, the higher the amount of hydrolyzed substrate, the higher the amount of glucose produced, as expected. However, a surprising result was that the conversion yield first increased rapidly when the substrate loading was increased from $1.5 \%$ to $3.75 \%$, and then became nearly constant, independent from substrate loading (Fig. 2). This means that the hydrolysis rate was nearly proportional to the initial substrate loading, even though it decreased over time when substrate consumption proceeded. Thus, a cellulose-toglucose conversion yield about $77 \pm 3 \%$ could be reached when wet substrate loading was between $3.75 \%$ and $5.2 \%(\mathrm{w} / \mathrm{v})$. As the conversion yield was not significantly different for $3.75 \%, 4.5 \%$, and $5.2 \%(\mathrm{w} / \mathrm{v})$ substrate proportion, the consequence is that the glucose concentration increased nearly proportionally to the substrate content up to $32 \pm 1 \mathrm{~g} / \mathrm{L}$ at $5.2 \%$ $(\mathrm{w} / \mathrm{v})$ substrate loading, corresponding to a conversion yield of $80 \% \pm 2 \%$ after 12 days of hydrolysis.

Similar outcomes on the evolution of glucose concentration had been already reported by several studies (Zhang et al., 2009; Qiu et al., 2017). For example, Qiu et al. (2017) investigated the effect of substrate loading during enzymatic hydrolysis using a pretreated wheat straw by phosphoric acid and hydrogen peroxide. Four substrate loadings $(2,10,15$, and $20 \%$ ) were tested, and it was pointed out that the highest substrate consistency led to the highest glucose concentration in the final hydrolysate. However, the cellulose-to-glucose conversion yield decreased slightly when the substrate loading increased.

Finally, contrary to expectations which predicted an increase in glucose concentration coupled to a decrease in yield when substrate content was increased, it was found that the lowest 
1 substrate loading investigated, $1.5 \%(\mathrm{w} / \mathrm{v})$, lead simultaneously to the lowest conversion yield $2(57 \% \pm 3 \%)$ and the lowest concentration of glucose $(6.7 \pm 0.3 \mathrm{~g} / \mathrm{L})$, whereas the best results were achieved for the highest proportion of substrate $(5.2 \% \mathrm{w} / \mathrm{v})$ in terms of yield and glucose content. Thus, by increasing pretreated substrate loading, higher concentrations of fermentable sugars are available and then, higher ethanol concentration can be achieved. Due to mixing issues resulting from the high viscosity of the cellulose suspension, experiments in $150 \mathrm{~mL}$ Erlenmeyer flasks had to be limited to $5.2 \%(\mathrm{w} / \mathrm{v})$ substrate loading, but a higher concentration will be tested in the scale-up assays in section 3.4, as better mixing condition could be achieved.

\subsection{Fermentation tests in flasks}

To produce bioethanol, the upstream enzymatic hydrolysis process must provide, as much as possible, a hydrolysate highly concentrated in glucose, accompanied by minor quantities of other hydrolyzed components (hemicellulose, inhibitors, etc.). The hydrolysates obtained from the enzymatic hydrolysis of 3.75\% (w/v) substrate loading present a satisfactory glucose concentration to critically investigate the capacity of the yeast to develop fermentation $(24.7$ g/L glucose). As already stated, (UE.H) corresponds to the medium without supplementation, whereas the culture medium is supplemented by the minerals and vitamins nutrients as described by Kristiansen (1994) in (E.H), both being prepared with an identical concentration of pure glucose.

Fig. 3 illustrates the evolution of glucose, ethanol and dry cell weight concentrations for the two hydrolysates tested (UE.H and E.H). Regarding the results, the sugars undergo ethanol fermentation in both cases, but the difference lies in the rates of glucose and of ethanol production, and consequently, in the concentration values compared at the same time.

In the Kristiansen's medium, all the sugars were consumed after 9 hours and the produced ethanol reached approximately $9.5 \pm 0.4 \mathrm{~g} / \mathrm{L}$ (data not shown). In the case of the (E.)H assay, 
1 the maximum concentration of ethanol was found to be $10.1 \pm 0.7 \mathrm{~g} / \mathrm{L}$ after $24 \mathrm{hrs}$., which

2 constituted $72 \%$ of the theoretical glucose-to-ethanol conversion yield ( $0.51 \mathrm{~g}$ ethanol per

3 gram of glucose). In parallel, the maximum concentration of ethanol was only $3.1 \pm 0.2 \mathrm{~g} / \mathrm{L}$ at

4 the same time for the (UE.H) assay. The latter concentration represented only $22 \pm 1 \%$ of the

5 theoretical glucose-to-ethanol conversion yield. This demonstrates the need to enrich the

6 hydrolysates with components necessary for the growth of yeast, such as the source of

7 phosphorus $\left(\mathrm{KH}_{2} \mathrm{PO}_{4}\right)$, and nitrogen $\left(\mathrm{NH}_{4}\right)_{2} \mathrm{SO}_{4}$, as well as various salts and vitamins

8 (Kristiansen, 1994). Table 2 summarizes the kinetic parameters calculated from the

9 fermentation inputs and outputs. Finally, the fermentation of the glucosidic hydrolysate by a

10 strain of Saccharomyces cerevisiae led us to reach an alcoholic fermentation yield close to

$1180 \%$ of the theoretical yield, which seems consistent with the absence of inhibiting

compounds produced during the pretreatment and hydrolysis steps.

\subsection{Scale-up of the enzymatic hydrolysis and fermentation processes}

The enzymatic hydrolysis scale-up was carried out in a $800 \mathrm{~mL}$ working volume under the same conditions applied to the other pretreated substrate loadings, except that better mixing conditions allowed to increase solid loading up to $7.5 \%(\mathrm{w} / \mathrm{v})$ pretreated sawdust mixture substrate. This value is closer to the solids loading range proposed by Stenberg et al. (2000) and Wingren et al. (2003). In these assays, the final glucose concentration was measured at about $34.5 \mathrm{~g} / \mathrm{L}$, which represents a cellulose-to-glucose conversion yield of $59 \pm 2 \%$ for up to 12 days (data not shown). This value is lower than in $150 \mathrm{~mL}$ flasks, which can probably be explained by the high viscosity of the $7.5 \%(\mathrm{w} / \mathrm{v})$ substrate suspension. The fermentation step was then performed in a $500 \mathrm{~mL}$ bioreactor using the obtained hydrolysate enriched with vitamins and minerals. The fermentation assays were carried out for $24 \mathrm{hrs}$.; the produced ethanol and the decrease in glucose contents were monitored during the fermentation. 
1 According to Fig. 4, approximately all the glucose was consumed after only 8 hours. The

2 produced ethanol in fermentation broth reached nearly $16 \pm 2 \mathrm{~g} / \mathrm{L}$ at the same time, which represents almost $80 \%$ of the theoretical glucose-to-ethanol conversion yield.

4 According to the information provided by Table 2, comparison of the control-based fermentation and the enriched hydrolysate fermented in bioreactor demonstrates the interest to use a bioreactor, in terms of yields and rates. Moreover, the high substrate proportion during enzymatic hydrolysis not only reduces the capital cost for installation of hydrolysis vessel, but it also more significantly provides a concentrated glucose stream for subsequent fermentation which will lead to important savings in the distillation cost (Zhang et al., 2009).

\subsection{Model for enzymatic hydrolysis}

From the previous sections, it emerges that enzymatic hydrolysis is the bottleneck of the process. Thus, modelling must focus on this step. Using the adsorption-reaction model developed in section $\mathbf{2 . 8}$ and inspired by Kadam et al. (2004) to fit enzymatic experimental data, adjusted model parameters were derived from the data monitored for the enzymatic hydrolysis performed at $3.75 \%(\mathrm{w} / \mathrm{v})$ substrate loading in $150 \mathrm{~mL}$ Erlenmeyer flasks, as described in section 3.2. The estimated value for maximum glucose concentration was found to be $19.3 \mathrm{~g} / \mathrm{L}$ versus $21.4 \pm 0.2 \mathrm{~g} / \mathrm{L}$ derived experimentally for $3.75 \%$ (w/v) substrate. Fig. 5 displays the comparison between calculated and experimental results after using the adjusted parameters in the model $\left(k_{1 r}=3.61 \mathrm{~g} / \mathrm{mg} . \mathrm{h}\right.$, and $\left.k_{2 r}=11.5 \mathrm{~g} / \mathrm{mg} . \mathrm{h}\right)$, not only for $3.75 \%$ substrate loading, but also for $4.5 \%$ and $5.2 \%(\mathrm{w} / \mathrm{v})$. The plot of glucose concentration as a function of time shows that the model correctly fits glucose production for the three concentrations until day 8 , whereas glucose production is underestimated for longer times, especially when loading is increased. However, the model was not able to predict correctly the scale-up in a $1000 \mathrm{~mL}$ bottle: it overestimated about $38.2 \mathrm{~g} / \mathrm{L}$ glucose production the experimental value at day 12 , while it underestimated experimental values at lower loading in 
1 Fig. 5. This result agrees with the decrease in conversion yield and with the effect of

2 suspension viscosity at high substrate loading that slows down mass transfer phenomena, as

3 Kadam's model assumes a Langmuir equilibrium model for enzyme adsorption, accounting

4 only for the kinetics of chemical steps. This highlights that more complex models are

5 probably required and that the respective influences of mixing conditions and dispersion

6 rheology must be studied for scale-up purpose.

\section{4. Conclusion}

8 The feasibility of lignocellulosic bioethanol production using a sawmill mixed feedstock of 9 softwood species was assessed. Enzymatic hydrolysis, applied to an undried microwaveassisted water/ethanol Organosolv pretreated substrate $(71 \% \mathrm{w} / \mathrm{w}$ cellulose) with particle size higher than $0.5 \mathrm{~mm}$, reached $80 \%$ saccharification yield with up to $5.2 \%$ (w/v) substrate loading. Higher loading decreased this yield, but higher ethanol concentration could be achieved from subsequent fermentation using Saccharomyces cerevisiae, e.g. 16 g/L when substrate loading was $7.5 \%(\mathrm{w} / \mathrm{v})$. As an outcome, this process which tends to a closed-loop biorefinery, is promising for regions where only mixed softwood feedstock is available.

\section{Acknowledgments}

This work was funded by Auvergne Rhône-Alpes Regional Council, and the European Regional Development Fund (FEDER/ERDF) to promote the valorization of local feedstocks (woodwastes) on a regional scale.

\section{References}

1. Akgul, M., Kirci, H., 2009. An environmentally friendly organosolv (ethanol-water) pulping of poplar wood. J. Environ. Biol. 30, 735-740. 
2. Alio, M.A., Tugui, O.-C., Vial, C., Pons, A., 2019. Microwave-assisted Organosolv pretreatment of a sawmill mixed feedstock for bioethanol production in a wood biorefinery. Bioresour. Technol. 276, 170-176. https://doi.org/10.1016/j.biortech.2018.12.078

3. Bahry, H., Pons, A., Abdallah, R., Pierre, G., Delattre, C., Fayad, N., Taha, S., Vial, C., 2017. Valorization of carob waste: Definition of a second-generation bioethanol production process. Bioresour. Technol. 235, 25-34. https://doi.org/10.1016/j.biortech.2017.03.056

4. Bhagia, S., Dhir, R., Kumar, R., Wyman, C.E., 2018. Deactivation of Cellulase at the AirLiquid Interface Is the Main Cause of Incomplete Cellulose Conversion at Low Enzyme Loadings. Sci. Rep. 8, 1-12. https://doi.org/10.1038/s41598-018-19848-3

5. Bradford, M.M., 1976. A rapid and sensitive method for the quantitation of microgram quantities of protein utilizing the principle of protein-dye binding. Anal. Biochem. 72, 248-254. https://doi.org/10.1016/0003-2697(76)90527-3

6. Bryngemark, E., 2019. Second generation biofuels and the competition for forest raw materials: A partial equilibrium analysis of Sweden. For. Policy Econ. 109, 102022. https://doi.org/10.1016/j.forpol.2019.102022

7. Chovau, S., Degrauwe, D., Van der Bruggen, B., 2013. Critical analysis of technoeconomic estimates for the production cost of lignocellulosic bio-ethanol. Renew. Sustain. Energy Rev. 26, 307-321. https://doi.org/10.1016/j.rser.2013.05.064

8. Dasari, R.K., Berson, R.E., 2007. The Effect of Particle Size on Hydrolysis Reaction Rates and Rheological Properties in Cellulosic Slurries, in: Mielenz, J.R., Klasson, K.T., Adney, W.S., McMillan, J.D. (Eds.), Applied Biochemistry and Biotecnology: The Twenty-Eighth Symposium Proceedings of the Twenty-Eight Symposium on Biotechnology for Fuels and Chemicals Held April 30-May 3, 2006, in Nashville, 
1 Tennessee. Humana Press, Totowa, NJ, pp. 289-299. https://doi.org/10.1007/978-160327-181-3_26

9. Fu, Y., Gu, B.-J., Wang, J., Gao, J., Ganjyal, G.M., Wolcott, M.P., 2018. Novel micronized woody biomass process for production of cost-effective clean fermentable sugars. Bioresour. Technol. 260, 311-320. https://doi.org/10.1016/j.biortech.2018.03.096

10. Ghose, T.K., 1987. Measurement of cellulase activities. Pure Appl. Chem. 59, 257-268. https://doi.org/10.1351/pac198759020257

11. Huang, R., Su, R., Qi, W., He, Z., 2010. Understanding the key factors for enzymatic conversion of pretreated lignocellulose by partial least square analysis. Biotechnol. Prog. 26, 384-392. https://doi.org/10.1002/btpr.324

12. Kadam, K.L., Rydholm, E.C., McMillan, J.D., 2004. Development and validation of a kinetic model for enzymatic saccharification of lignocellulosic biomass. Biotechnol. Prog. 20, 698-705. https://doi.org/10.1021/bp034316x

13. Kang, K.-Y., Hwang, K.-R., Park, J.-Y., Lee, J.-P., Kim, J.-S., Lee, J.-S., 2018. Critical Point Drying: An Effective Drying Method for Direct Measurement of the Surface Area of a Pretreated Cellulosic Biomass. Polymers 10, 676. https://doi.org/10.3390/polym10060676

14. Kinnarinen, T., Shakhanova, M., Hietanen, E., Salmimies, R., Häkkinen, A., LouhiKultanen, M., 2012. Effect of mixing on enzymatic hydrolysis of cardboard waste: Saccharification yield and subsequent separation of the solid residue using a pressure filter. Bioresour. Technol. 110, 405-411. https://doi.org/10.1016/j.biortech.2012.01.138

15. Kristiansen, B. (Bjørn), 1994. Integrated design of a fermentation plant : the production of baker's yeast. Weinheim; New York : VCH. 
1 16. Lebaz, N., Cockx, A., Spérandio, M., Morchain, J., 2015. Population balance approach for

2 the modelling of enzymatic hydrolysis of cellulose. Can. J. Chem. Eng. 93, 276-284. https://doi.org/10.1002/cjce.22088

17. Mukasekuru, M.R., Hu, J., Zhao, X., Sun, F.F., Pascal, K., Ren, H., Zhang, J., 2018. Enhanced High-Solids Fed-Batch Enzymatic Hydrolysis of Sugar Cane Bagasse with Accessory Enzymes and Additives at Low Cellulase Loading. ACS Sustain. Chem. Eng. 6, 12787-12796. https://doi.org/10.1021/acssuschemeng.8b01972

18. Mupondwa, E., Li, X., Tabil, L., Sokhansanj, S., Adapa, P., 2017. Status of Canada’s lignocellulosic ethanol: Part I: Pretreatment technologies. Renew. Sustain. Energy Rev. 72, 178-190. https://doi.org/10.1016/j.rser.2017.01.039

19. Qiu, J., Ma, L., Shen, F., Yang, G., Zhang, Y., Deng, S., Zhang, J., Zeng, Y., Hu, Y., 2017. Pretreating wheat straw by phosphoric acid plus hydrogen peroxide for enzymatic saccharification and ethanol production at high solid loading. Bioresour. Technol. 238, 174-181. https://doi.org/10.1016/j.biortech.2017.04.040

20. Sangseethong, K., Meuniers-Goddik, L., Tantasucharit, U., Liaw, E. -T., Penner, M.H., 1998. Rationale for particle size effect on rates of enzymatic saccharification of microcrystalline cellulose. J. Food Biochem. 22, 321-330.

21. Sarks, C., Jin, M., Sato, T.K., Balan, V., Dale, B.E., 2014. Studying the rapid bioconversion of lignocellulosic sugars into ethanol using high cell density fermentations with cell recycle. Biotechnol. Biofuels 7, 73. https://doi.org/10.1186/1754-6834-7-73

22. Selig, M., 2008. Enzymatic saccharification of lignocellulosic biomass laboratory analytical procedure (LAP) : issue date, 3/21/2008 /. National Renewable Energy Laboratory, Golden, Colo. :

23. Shastri, Y.N., Miao, Z., Rodríguez, L.F., Grift, T.E., Hansen, A.C., Ting, K.C., 2014. Determining optimal size reduction and densification for biomass feedstock using the 
1 BioFeed optimization model. Biofuels Bioprod. Biorefining 8, 423-437.

24. Stenberg, K., Bollók, M., Réczey, K., Galbe, M., Zacchi, G., 2000. Effect of substrate and cellulase concentration on simultaneous saccharification and fermentation of steampretreated softwood for ethanol production. Biotechnol. Bioeng. 68, 204-210. https://doi.org/10.1002/(SICI)1097-0290(20000420)68:2<204::AID-BIT9>3.0.CO;2-4

25. Tervasmäki, P., Sotaniemi, V., Kangas, J., Taskila, S., Ojamo, H., Tanskanen, J., 2017. A discretized model for enzymatic hydrolysis of cellulose in a fed-batch process. Bioresour. Technol. 227, 112-124. https://doi.org/10.1016/j.biortech.2016.12.054

26. Tsai, C.-T., Morales-Rodriguez, R., Sin, G., Meyer, A.S., 2014. A Dynamic Model for Cellulosic Biomass Hydrolysis: a Comprehensive Analysis and Validation of Hydrolysis and Product Inhibition Mechanisms. Appl. Biochem. Biotechnol. 172, 2815-2837. https://doi.org/10.1007/s12010-013-0717-x

27. Wang, Z., Feng, H., 2010. Fractal kinetic analysis of the enzymatic saccharification of cellulose under different conditions. Bioresour. Technol. 101, 7995-8000. https://doi.org/10.1016/j.biortech.2010.05.056

28. Wingren, A., Galbe, M., Zacchi, G., 2003. Techno-Economic Evaluation of Producing Ethanol from Softwood: Comparison of SSF and SHF and Identification of Bottlenecks. Biotechnol. Prog. 19, 1109-1117. https://doi.org/10.1021/bp0340180

29. Wojtusik, M., Zurita, M., Villar, J.C., Ladero, M., Garcia-Ochoa, F., 2016. Influence of fluid dynamic conditions on enzymatic hydrolysis of lignocellulosic biomass: Effect of mass transfer rate. Bioresour. Technol. 216, 28-35. https://doi.org/10.1016/j.biortech.2016.05.042 
1 30. Ye, Z., Berson, R.E., 2011. Kinetic modeling of cellulose hydrolysis with first order

2 inactivation of adsorbed cellulase. Bioresour. Technol. 102, 11194-11199. https://doi.org/10.1016/j.biortech.2011.09.044

31. Yeh, A.-I., Huang, Y.-C., Chen, S.H., 2010. Effect of particle size on the rate of enzymatic hydrolysis of cellulose. Carbohydr. Polym. 79, 192-199. https://doi.org/10.1016/j.carbpol.2009.07.049

32. Zeng, M., Mosier, N.S., Huang, C.-P., Sherman, D.M., Ladisch, M.R., 2007. Microscopic examination of changes of plant cell structure in corn stover due to hot water pretreatment https://doi.org/10.1007/s00253-009-1883-1

33. Zhang, X., Qin, W., Paice, M.G., Saddler, J.N., 2009. High consistency enzymatic and enzymatic hydrolysis. Biotechnol. Bioeng. 97, 265-278. https://doi.org/10.1002/bit.21298 hydrolysis of hardwood substrates. Bioresour. Technol. 100, 5890-5897. https://doi.org/10.1016/j.biortech.2009.06.082

34. Zhang, Y., Xu, B., Zhou, W., 2014. On a novel mechanistic model for simultaneous enzymatic hydrolysis of cellulose and hemicellulose considering morphology. Biotechnol. Bioeng. 111, 1767-1781. https://doi.org/10.1002/bit.25244

35. Zhao, X., Cheng, K., Liu, D., 2009. Organosolv pretreatment of lignocellulosic biomass for enzymatic hydrolysis. Appl. Microbiol. Biotechnol. 82, 815-827. 


\section{$1 \quad$ Figure captions}

2 Fig. 1: Evolution of cellulose-to-glucose conversion vs. time at 1.5\% (w/v) initial substrate

3 content: effects of drying (wet vs. dry substrate), particle size ( $>0.5 \mathrm{~mm}$ vs. $<0.5 \mathrm{~mm}$ ) and

4 enzyme loadings (50 vs. $70 \mathrm{FPU} / \mathrm{g}$ ).

$5 \quad$ Fig. 2: Analysis of enzymatic hydrolysis of pretreated sawdust at four different substrate

6 loadings $(1.5 \%, 3.75 \%, 4.5 \%$, and $5.2 \% \mathrm{w} / \mathrm{v})$, monitoring the glucose concentration and the

7 cellulose-to-glucose conversion yield.

8 Fig. 3: Evolution of ethanol, biomass and glucose concentrations in the submerged

9 fermentation broth in flasks (a): enriched hydrolysate (E.H), and (b): unenriched hydrolysate

10 (UE.H).

11 Fig. 4: Evolution of glucose, ethanol and yeast cells concentrations during fermentation scale-

12 up in the bioreactor.

13 Fig. 5: Kinetic model validation based on enzymatic hydrolysis conducted in Erlenmeyer flasks

14 for 3.75, 4.5, and 5.2\% (w/v) pretreated substrate loading: (a) the glucose concentration; (b) the

15 cellulose-to-glucose conversion yield. 


\section{Table captions}

2 Table 1: Evolution of size reduction costs of Miscanthus and switchgrass as a function of the

3 output particle size using a hammer mill (data extracted from Shastri et al., 2014).

4 Table 2: Comparison of kinetic data obtained from the different fermentation trials. 